\title{
UTILIZACIÓN DE LAS TÉCN ICAS BIOTECNOLÓGICAS EN LOS PROGRAMAS DE PREVENCIÓN DEL VIRUS DE LA TRISTEZA DE LOS CIITRICOS EN EL ESTADO DE VERACRUZ
}

\section{Lourdes G . Iglesias, Paula Rojas Mencio}

Centro de Genética Forestal. Universidad Veracruzana. México

\section{Jorge L. Enríquez}

Consejería de Agricultura, Agua y Medio Ambiente. Murcia

\section{INTRODUCCI N}

Los cítricos constituyen el cultivo de mayor importancia en la Fruticultura M exicana, tanto por el área que se destina a su cultivo en 17 estados de la República, como por los empleos que genera en la producción, la industria y la comercialización nacional e internacional (de la 0 sa, 1998; Gómez et al., 1998).

ActualmenteM éxico ocupa el cuarto lugar como productor de cítricos en el ámbito mundial de naranjas y primer lugar en la producción de limas ácidas solamente superado por Brasil, Estados Unidos y China(GISE, S.A. deC.V., 1996, citado por dela O sa, 1998). D entro de los cítricos, la naranja y el limón mexicano son las especies más cultivadas, siguiéndole en orden de importancia, las mandarinas, lastoronjas, las limasy el limón real (Chagolla, 1990).

En el estado de Veracruz se cuenta en la actualidad con más de 150.000 hectáreas de cítricos sembradas, delas cualesalrededor del $85.2 \%$ corresponde a $\mathrm{N}$ aranjas, el $80 \%$ a $\mathrm{M}$ andarinas, el $4.5 \%$ a $\mathrm{Li}$ món Persa y el $0.3 \%$ aToronja. Esto representa más de la tercera parte de la superficie y producción citrícola nacional (Gómez et al., 1998).
La propagación de este grupo de especies se lleva a cabo casi exclusivamente mediante injertos sobre patrones de semillas, que en muchos casos tienen un origen apomíctico. Estetipo de propagación que en general requiere de una gran superficie, resulta algo más tardado, se encuentra limitado por la época del año y la obtención de semilla adecuada, además de que puede promover la transmisión de enfermedades, especialmente sistémicas ( $M$ icroplasmas, virus, viroides) (Chagolla, 1990).

El virus delaTristeza de los Cítricos (VTC) constituye hoy en día la enfermedad viral, de carácter letal, que más daño ha ocasionado a la citricultura mundial (O rozco, 1996). D esde fines de la década del 30 hasta los últimos años, esta enfermedad ha ocasionado la muerte de 50 millones de árboles en diversos países (O rozco, 1996). En particular el VTC ha destruido la citricultura de Sudamérica (especialmente en países como Argentina, Brasil y Venezuela) y ha dañado sensiblemente la citricultura de países como Estados U nidos, Españael srael (Roistacher et al., 1994; RIAC, 1995).

En gran parte estos daños pueden ser atribuidos al hecho de que más del $90 \%$ de los árboles de los 6 países de mayor producción y exportación de cítri- 
cos en la región de América Latina y el Caribe se encuentran injertados sobre protainjertos de naranjo agrio (Citrusaurantium L.) (RIAC, 1995), el cual además de ser altamente susceptible al virus de la tristeza de los cítricos, resulta también muy sensible a la Psorosis y a los N emátodos (Curti-D íaz et al., 1996).

M éxico por su parte posee el $95 \%$ del total de sus plantaciones susceptibles al VTC, ya que están injertados sobre patrones de naranjo agrio o son de «piefranco» (sin injertar) como los limones «C olima» 0 «C riollo»(C. aurantifolia L.), todos ellos extremadamente susceptibles al VTC, por lo que al igual que los países antes mencionados, la citricultura mexicana no escapa de esta amenaza (O rozco, 1996).

C omo indicara R oistacher et al ., (1994) cada vez se encuentra más cerca de M éxico el mayor enemigo de los cítricos. Actualmente M éxico se encuentra rodeado de esta epidemia por el Sur (G uatemala y Belice), por el Este (Las Antillas), por el N oroeste (Florida), por el Norte (Texas) y por el Noroeste (California)(de la O sa, 1998).

El vector más eficiente de la enfermedad, que es el áfido Toxoptera citricidus Kirkardly (M eneghini, 1946; Costa y Grant, 1951, citados por Brunt et al., 1996), elemento que desencadena con su diseminación la alta mortalidad de plantas, ha sido reportado en varios países de Centroamérica, en migración hacia el N orte, así como en las I slas del $\mathrm{Ca}$ ribe(incluyendo a C uba). D esdeN oviembre de 1995 sele ha detectado también en el estado de la Florida y en 0 ctubre de 1996 llegó a Belice, de modo que se encuentra a solo $150 \mathrm{Km}$ del estado de Q uintana Roo (de la O sa, 1998).

En el XIII Congreso Internacional de Fitopatología, desarrollado en Guadalajara, Jalisco, en Septiembre de 1996, se informó por la Dirección General de Sanidad Vegetal de la SAGAR, la presencia del VTC, en sus líneas asintomáticas, en 7 estados de la República, hoy en día éste se ha extendido yaa 12 Estados (dela 0 sa, 1999, com.pers).

D e hecho, desde 1986 se ha reportado la presencia de síntomas del VTC en el estado de Veracruz y desde 1992 se constató su presencia en el campo experimental de Inmecafé en los viveros «EI papayo» y «El Limoncito» en T lapacoyán y en la huerta «Ex-Fira» deM artínez delaTorre. Es por ello que se ha implementado una norma en el Estado que instituye el «Plan de Emergencia contra el virus de la Tristeza» (SARH , 1993).

Aunque en el estado de Veracruz esta enfermedad se ha manifestado en focos aislados y aparentemente con una raza débil del virus (R ocha-Peña, 1995), no se descarta la posibilidad de que se haya distribuido a otras áreas citrícolas dentro y fuera del Estado. La amenaza de la tristeza se torna más preocupante particularmente en las regiones productoras de limón mexicano, ya que esta especie citrícola es altamente vulnerable al VTC (O rozco, 1996).

Como medida de prevención ante esta seria enfermedad desde hace años la mayoría de los países citricultores afectados por el VTC han ido sustituyendo el naranjo agrio (Citrus aurantium L.) por portainjertos tolerantes al VTC como son: los Citranges «troyer» y «carrizo» (Citrus sinensis $L$. O sbeck x Poncirus trifoliata L. Raf.), la mandarina «Cleopatra» (Citrus reticulata Blanco), la lima «R angpur» (Citrus aurantifolia L.) y el limón Volkameriano (Citrus volkameriana Pasq.)(RIAC, 1995; M edina, 1995; O rozco, 1996).

Algunos de estos portainjertos como los C itranges «troyer» y «carrizo» (Citrus sinensis L. O sbeck $x$ Poncirustrifoliata L. Raf.) y el Citrumelo «Swingle» (Citrus paradis $M$ acf. x Poncirus trifoliata L. Raf.), además de tolerantes al VTC, pertenecen al grupo de portainjertos cuyo efecto sobre la calidad del fruto es alto (Padrón, 1991).

Aunque en M éxico se han desarrollado diversas acciones preventivas contra el VTC (López, 1994; Colli y Cárdenas, 1995; IN EG I, 1996), no secuenta en la magnitud de lo necesario con un programa de certificación de plantas de cítricos que permita la producción de portainjertos tolerantes al VTC, ni de yemas certificadas de las principales variedades comerciales, de manera que los productores puedan contar con plantas certificadas como medio de defensa ante esta enfermedad (O rozco, 1996).

Es por ello que la mayoría de los productores de la región del Golfo siguen empleando el naranjo agrio (Citrusaurantium L.) como portainjerto, dada fundamentalmente la poca disponibilidad de semilla y el gran desconocimiento que tienen sobre el 
comportamiento de otros portainjertos en sus plantaciones; por estas razones al gunos citricultores han optado por plantar alternadamente un patrón agrio y uno tolerante al VTC dentro de cada hilera; de este modo esperan asegurar una supervivencia de al menos un $50 \%$ de sus árboles en caso de que se presente algunas razas severas de este virus (Curti-D íaz et al., 1996).

D e acuerdo con López (1994), en la zona norte de Veracruz, donde se encuentran diferencias notables en suelos y clima, no se puede recomendar el uso de un solo portainjerto como sustituto del naranjo agrio, por lo que afirma que la nueva tecnología exige más precisión en la selección de un grupo numeroso de portainjertos, ya que cada uno de ellos presenta limitantes a las propiedades extremas físicas y química del suelo y a otras enfermedades.

Cabe resaltar que ante esta situación, desde hace algunos años, se han estado desarrollando algunas acciones para lograr un adecuado control y prevención del VTC por parte del Centro Estatal de Sanidad Vegetal de Veracruz (CESVER), en coordinación con el Instituto Tecnológico Agropecuario No. 18 (ITA-18) de Ciudad Cardel, Ver., las que han conllevado, entre otras, al establecimiento de un Vivero de portainjertos de cítricos tolerantesal VTC, que se ha venido caracterizando desde un punto de vista morfoagronómico (Coto y Rodríguez, 1998; Gómez et al., 1998).

Las investigaciones dirigidas en particular al estudio, selección y propagación de portainjertos que proporcionen las mejores características hortícolas, con los mejores requerimientos de control de plagas y deenfermedades, constituyeuno de los fundamentos necesarios, para cual quier industria citrícola viable y por ello cada país, con una citricultura viable, debe de, con alta prioridad, adoptar un programa adecuado de producción de material de propagación (RIAC, 1995).

La aplicación de las técnicas biotecnológicas con este propósito ha sido una vía muy útil para apoyar los programas de producción y certificación de portainjertos y yemas tolerantes al VTC que por la vía convencional se desarrollan en el Estado. Es por ello que el presente trabajo esta dirigido a revisar los principales avances biotecnológicos que al respecto se han logrado con particular referencia a los que actualmente se han obtenido dentro del Estado.

\section{REVISI N DE LOS AVAN CES ALCAN - ZADOS EN LOS TRABAJOS DE PROPA- GACI N IN VITRO DEPORTAIN J ERTOS DE C TRICOS TO LERANTES AL VTC}

El empleo de las técnicas biotecnológicas como la micropropagación, ya sea a través del cultivo de meristemos y de microinjertos, en combinación 0 no con las técnicas de termoterapia, así como la inducción del proceso de embriogénesis somática, constituyen en la actualidad alternativas muy prometedoras para obtener plantas de cítricos libres de virus. Es por ello queen losúltimos años se ha puesto un mayor énfasis en el empleo de las técnicas de cultivo de células somáticas y otras técnicas moleculares, en el mejoramiento genético de los cítricos (Gill et al., 1995).

En particular en cítricos, los métodos de multiplicación aséptica presentan numerosas ventajas, con respecto a los métodos tradicionales de propagación, debido, a que permiten obtener elevadas tasas de multiplicación en corto tiempo, empleando espacios reducidos y sin las limitaciones impuestas por la época del año, además de que posibilitan la eliminación de patógenos no obligados y promueven la liberación depatógenos sistémicos (Chagolla, 1990). Asimismo, como indicara M as et al. (1991), me diante esta vía se facilita el transporte e introducción de material vegetativo, sin el riesgo detransmisión de enfermedades.

Los primeros trabajos de propagación in vitro en cítricos se realizaron desde la década de los sesenta, con la inducción de embriones nucelares en tres especies monoembriónicas de cítricos (Rangan et al., 1968). D esde entonces se han desarrollado nume rosos trabajos para la propagación de cítricos a partir detejidos nucelares deóvulosfertilizados (Rangan et al, 1969, citado por Chaturvedi y M itra, 1974) y no fertilizados (Button y Borman, 1971; M itra y Chaturvedi, 1972, citados por Chaturvedi y M itra, 1974).

Sin embargo además de tediosos, los métodos antes mencionados poseen entre otros inconvenien- 
tes el que solamente se puedan disponer de óvulos que se encuentren en un estadio apropiado de desarrollo en un corto período del año, además de que las plántulas obtenidas por esta vía muestran características dejuvenilidad (Chaturvedi y M itra, 1974). Estas características se manifiestan en forma de árboles muy altos y espinosos, más lentos para entrar en fructificación, producción alternante más marcada, un mayor grosor de la corteza del fruto y pulpa más áspera (M onteverde et al., 1992).

Por otra parte, el cultivo de meristemos que ha resultado exitosos en varias especies vegetales para limpiar materiales infectados por virus, no siempre ha dado buenos resultados en cítricos (Litz et al., 1985; G ravina y Piestum, 1991). Esta técnica que constituye la ruta más fácil y la que menos cambios genéticos provocan - ya que no requiere de la iniciación y diferenciación deórganos adventicios, sino solamente desarrollar los puntos de crecimiento pre sentes en las yemas- ha sido entre otros empleada por M osella y Ascui (1985), Lukman et al. (1990), O mura y H idaka (1992) y Baruah et al. (1996). H oy en día, como indicara, Baldwin (1993), el cultivo de meristemo se ha adaptado muy bien para la producción comercial de yemas de cítricos libres de virus, fundamentalmente en el estado de la Florida, Estados Unidos.

En M éxico, Rodríguez (1986), citado por Chagolla (1990), cultivó explantes de yema nodal de plantas maduras de dos tipos limoneros mexicanos, cultivados bajo condiciones de invernadero y obtuvo, al igual queK itto y Young (1981), bajas tasas de multiplicación (alrededor de 3 brotes por yema) y similares dificultades para lograr el enraizamiento de las vitroplántulas obtenidas. Resultados similares fueron obtenidos también por M edina (1995).

Lukman et al. (1990) obtuvieron mejores resultados en el cultivo demeristemos de citrange «troyer» empleando primeramente medio líquido M S (M urashige y Skoog, 1962) suplementado con $1 \mathrm{mgL}^{-1}$ de Ácido Giberélico $\left(\mathrm{GA}_{3}\right)$ y $0.08 \mathrm{mgL}^{-1}$ de Benziladenina (BA) y luego medio M S sólido suplementado con $0.01 \mathrm{mgL}^{-1}$ de Ácido naftaleneacético (AN A), $0.5 \mathrm{mgL}^{-1}$ de BA y $1.0 \mathrm{mgL}^{-1}$ de $\mathrm{GA}_{3}$.

Sing et al. (1994) lograron sin embargo inducir un mayor número de brotes (alrededor de 6 brotes por yema) a partir de cultivo de ápices de 5 a $6 \mathrm{~mm}$ de longitud provenientes de plantas maduras de Citrus reticulata Blanco $\mathrm{Cv}$ mandarina «k hasi » $\mathrm{C}$. limon Burm.f.cv «limón Asam» en un medio MS, suplementado con BAP ( 6 benzilaminopurina), AN A y KIN (6-furfuril aminopurina). Estos autores constataron la importancia del empleo de una combinación de AN A, AIB (ácido indolbutírico) y BAP para lograr un mayor éxito en la formación de brotes múltiples y durante el proceso de enraizamiento y recomendaron para lograr una más elevada tasa de proliferación de brotes en ambas especies, el empleo de medio MS suplementado con $1 \mathrm{mgL}^{-1}$ de $B A, 0.5 \mathrm{mgL}^{-1}$ de Kinetina y $0.5 \mathrm{mgL}^{-1}$ de AN A.

A falta de una metodología eficiente para el cultivo in vitro de meristemos, que permitiera la liberación de virus y demás patógenos sistémicos en cítricos, se implementó la técnica de M icroinjertación. Esta técnica desarrollada primeramente por M urashige et al. (1972) y puesta a punto por N avarro et al. (1975), permite la obtención de plantas libres de virus mediante la inducción al desarrollo de un explante demeristemo apical sobreel épicotilo decapitado de una plántula originada a partir de semilla, en un medio apropiado y bajo condiciones asépticas.

D e acuerdo con N avarro et al. (1975) es posible lograr entre un 30-50\% de éxito en la aplicación de esta técnica y en al gunos casos se ha reportado hasta un 90\% (Chen et al, 1992). La técnica de microinjerto posee además la ventaja de que permite la eliminación no solo del virus de la tristeza sino también de otros virus como la Psorosis y la Exocortis (M onteverde et al., 1992; González et al., 1980), como indicara Roistacher el al (1994) citado por Gravina y Piestun (1991), la no detección de virus en 400 plantas de distintas variedades de Citrus obtenidas por microinjerto y cuya fuente original se encontraba afectada por uno o más de los virus de: Psorosis, A marillamiento, Concavidad gomosa, $\mathrm{H}$ oja rasgada, Infección jaspeada, Xyloporosis, Exocortis y Spiroplasma citri, entre otros, demuestra la alta eficiencia de ésta técnica para la eliminación de distintas razas de estos virus.

Por otra parte se ha indicado (N avarro et al., 1975) que los microinjertos obtenidos no muestran 
características de juvenilidad, lo que les permite incluso florecer y fructificar en menos de un año. Es por ello que esta técnica se ha utilizado en muchos países citrícolas del mundo para obtener yemas libres de virus, con vistas a su uso en la propagación comercial de cítricos (González et al., 1977; Starrantino, 1992; M onteverdeet al., 1992; G ravina y Piestum, 1991; Paiva et al., 1993; Zarei y Rahimian, 1997; Mukhopadhyay et al., 1997, Parthasarathy et al., 1997).

La frecuencia de éxito de los microinjertos se incrementa con el tamaño del explante meristemático, pero disminuye el porcentaje de plantas libres de virus ( $N$ avarro et al., 1975), aunque muchas veces esta relación depende del patógeno (Litz et al., 1985). Por ello se consideran óptimos para lograr un buen equilibrio entre el porcentaje de microinjertos prendidos y la eliminación de virus, el empleo de explantes meristemáticos, cuyos tamaños oscilen entre $0.12-0.18 \mathrm{~mm}$ y que posean de 2 a 4 primordios foliares (N avarro et al., 1975; Gravina y Piestun, 1991).

En M éxico, como apuntara Chagolla (1990), se ha logrado obtener plantas de cítricos libres de virus siguiendo la metodología propuesta por $\mathrm{N}$ avarro et al. (1975), gracias entre otros a los trabajos desarrollados en el Campo Experimental «General Terán» del IN IFAP.

D e igual forma se ha logrado inducir en cítricos el proceso de embriogénesis somática especialmente en aquellas especies poliembriónicas (Kunitaki et al., 1991; Gill et al., 1994; Gill et al., 1995; Belkoura et al., 1995). Sin embargo los callos embriogénicos producidos pueden presentar cierta inestabilidad genética, que no los hacen muy apropiados para su uso como método de propagación.

M uy empleada ha sido también, la regeneración de plantas de cítricos por la vía sobre todo de la organogénesis directa (Litz et al., 1985). Esta técnica ha sido descrita en diversos tejidos como: raíces (Sauton et al., 1982; Starrantino y Caruso, 1987; Raman et al., 1992), secciones de hojas (C haturvedi y M itra, 1974) y secciones del tallo (M oore, 1986; Raman et al., 1992; M as et al., 1994; $H$ arada et al., 1996; T hirumalai y Thamburaj, 1996).

D entro de estas se han logrado muy buenos resultados con el empleo en particular de explantes a partir de segmentos del tallo (C an et al., 1992; PérezMolphe-Balch y O choa-Alejo, 1997).

Algunos autores (Rangaswamy, 1961; M urashige y Tucker, 1969, citados por M edina, 1995) consideran que las condiciones de cultivo más adecuadas para la inducción de la organogénesis en cítricos requieren mantener los cultivos a una intensidad luminosa de 3,000 lux por un período diario de 12 a 16 horas y a una temperatura de 25 a $30^{\circ} \mathrm{C}$. Los mismos autores coinciden en señalar que la sacarosa satifface los requisitos en la mayoría de los tejidos de cítricos si se emplea en una concentración de $5 \%(\mathrm{p} / \mathrm{v})$.

D e forma general, como apuntara Espinoza (1994), el análisis de los resultados sobre cultivos in vitro en cítricos muestran diferencias en las respuestas de los explantes - aún usando técnicas similares-, dada la influencia entreotros de factores como son: tipo detejido, preparación delos mismos, composición química del medio de cultivo y condiciones de cultivo. Esto ha conllevado a que el número de brotes obtenidos no haya sido muy el evado comparado con otras especies.

Teniendo en cuenta estos resultados que demuestran la utilidad del empleo de las técnicas de cultivo de tejidos para lograr el saneamiento y micropropagación de portainjertos de cítricos tolerantes al virus de la tristeza preservan do la estabilidad genética necesaria, se comenzaron desde 1999 a desarrollar algunos trabajos en esta dirección en el Instituto de Genética Forestal de la U niversidad Veracruzana.

Como parte de los trabajos realizados se ha logrado la inducción del proceso de organogénesis indirecta, así como se han iniciado los trabajos de microinjertos para la micropropagación de dos portainjertos (Citranges Troyer y Carrizo) tolerantes al V irus delaTristeza de los cítricos (Fotos 1 y 2).

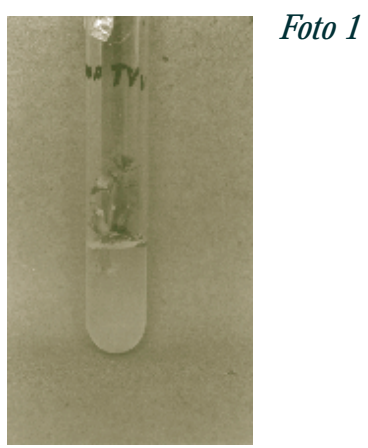

Foto 2

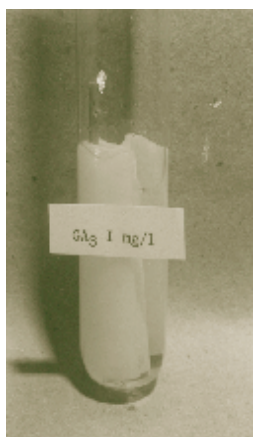


III. REVISIÓN DE LOS AVAN CES ALCAN ZADOS EN LOS TRABAJ OS DE CARACTERIZACIÓN BIOQUÍMICA DE PORTAINJ ERTOS DE CÍTRICOS TOLERANTES AL VTC

$\mathrm{N}$ o abundan en la literatura referencias sobre el uso de marcadores bioquímicos y moleculares para evaluar la estabilidad genética del material micropropagado y caracterizar las poblaciones de portainjertos de cítricos tolerantes al VTC.

$C$ abe mencionar entre otros a algunos autores (M as et al., 1986; Grosser et al., 1993; Bowman 1994) que han empleado los análisis isoenzimáticos para evaluar la estabilidad genética de las vitroplántulas obtenidas. 0 tros autores han empleado las variantes isoenzimáticas como marcador genético paralaidentificación de posturas nucelares y cigóticas en progenies de cítricos (Iglesias et al., 1974; I glesias y Lima, 1978), para estudiar el polimorfismo bioquímico en éste género (Torres et al., 1978; Torres et al., 1985), así como para identificar los productos de fusión de protoplastos (Tusa et al., 1990).

Sin embargo, debido a la estrecha relación genética existente entre los cultivares de cítricos, los sistemas isoenzimáticos analizados hasta la fecha han revelado la existencia de un bajo nivel de polimorfismo (Roose, 1988, citado por D eng et al., 1995). Es por ello que en los últimos años se ha resal tado la utilidad del empleo en cítricos de otros marcadores moleculares como es el Polimorfismo de AD N amplificado al azar (RAPD) para la identificación de genotipos de Citrus estrechamente relacionados (Luro et al., 1992; D eng et al., 1995; M arino et al., 1997). D e acuerdo con D eng et al. (1995), esta técnica permite detectar en forma altamente repetible simples cambios de base en el AD N genómico si se examinan suficientes cebadores.

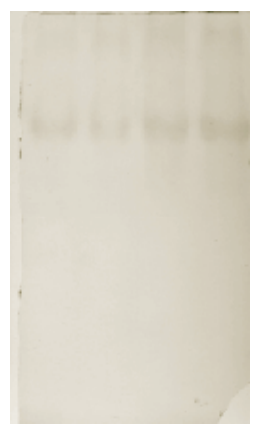

Foto 3

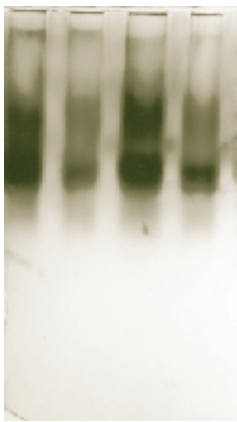

M arino et al. (1997) empleando esta técnica para caracterizar la diversidad genética dentro del germoplasma de C. limonia, lograron detectar 100 marcadoresRAPD polimórficosque permitió distinguir incluso a clones morfológicamente idénticos.

Los trabajos que actual mente se desarrollan mediante el uso de marcadores bioquímicos en el Instituto de $G$ enética Forestal han revelado la existencia de un marcado monomorfismo en la composición de isoenzimas peroxidasas y forfatasas ácidas (Fotos 3 y 4) en ambos portainjertos en estudio.

En otros sistemas isoenzimáticos analizados (esterasas y polifenoloxidasas) se ha detectado al gunas variantes polimórficas (datos no mostrados) que pueden servir de base no sólo para complementar posibles trabajos de identificación varietal de portainjertos de cítricos sino también como una vía de evaluar la estabilidad genética en el material micropropagado.

\section{NOTA DE LA REDACCIÓN:}

Por limitaciones de espacio no se ha podido incluir la lista completa de referencias bibliográficas que acompaña a este artículo. Los interesados en obtenerla en formato electrónico pueden solicitarla directamente a la dirección de correo electrónico de Cuadernos de Biodiversidad. 